\title{
Upregulation of miR-542-3p inhibits the growth and invasion of human colon cancer cells through PI3K/AKT/survivin signaling
}

\author{
CHUANG YANG, MING-HUAN WANG, JUN-DE ZHOU and QIANG CHI \\ Department of General Surgery, The Second Affiliated Hospital of Harbin Medical University, \\ Harbin, Heilongjiang 150086, P.R. China
}

Received May 25, 2017; Accepted July 27, 2017

DOI: 10.3892/or.2017.6054

\begin{abstract}
The present study was designed to assess the expression of microRNA-542-3p (miR-542-3p) in human colon cancer and investigate the possible molecular mechanisms underlying the effect of miR-542-3p on the growth and invasion of colon cancer cells. We found that miR-542-3p expression was downregulated in colon cancer patient tissues, compared with that observed in the control group. Silencing of miR-542-3p expression significantly promoted cell viability and inhibited apoptosis. In addition, overexpression of miR-542-3p significantly reduced cell viability and promoted apoptosis in colon cancer cells. Meanwhile, silencing of miR-542-3p expression significantly suppressed PI3K and p-AKT and survivin protein expression, while overexpression of miR-542-3p significantly induced PI3K and p-AKT and survivin protein expression in colon cancer cells. PI3K inhibitor (LY294002) or survivin inhibitor (YM155) suppressed PI3K/AKT/survivin signaling and increased the anticancer effects of miR-542-3p on the apoptosis in colon cancer. The present study demonstrated that upregulation of miR-542-3p inhibited the growth and invasion of colon cancer cells through PI3K/AKT/survivin signaling, highlighting a novel therapeutic approach for the treatment of colon cancer.
\end{abstract}

\section{Introduction}

Modern lifestyle trends, such as a high-fat diet, have rendered colon cancer as one of the most highly fatal tumors worldwide (1). The multi-gene and multi-step carcinogenic pathway, which is the traditional adenoma-adenocarcinoma pathway, has been widely accepted. This pathway has the morphological manifestations of intestinal epithelial hyperplasia, adenoma and invasive carcinoma in succession. It manifests as gradual

Correspondence to: Dr Chuang Yang or Dr Qiang Chi, Department of General Surgery, The Second Affiliated Hospital of Harbin Medical University, 246 Xuefu Road, Harbin, Heilongjiang 150086, P.R. China

E-mail: phdych@163.com

E-mail: tjwoy939474@126.com

Key words: miR-542-3p, colon cancer, PI3K, AKT, survivin superposition of staged oncogene mutation activation and tumor-suppressor gene inactivation at the molecular biological level. Key steps during colon cancer genesis, such as transformation and evolution, are associated with oncogene activation or tumor-suppressor gene inactivation (2). The former refers to the process where normal cells transform into cancer cells under oncogene induction. The latter represents cellular hyperplasia with gene instability and the acquisition of all malignant heterogeneities of tumor cells. As well known, early diagnosis is of crucial significance to the therapeutic effectiveness in colon cancer. Therefore, determining early lesions as well as the biomarkers during all evolutionary stages of colon cancer is of vital importance (3).

MicroRNAs (miRNAs) are non-coding RNA molecules with a length of 18-22 nt. They regulate gene expression through targeted binding of the $3^{\prime}$ untranslated region (3'UTR) terminal of mRNA molecules (4). In recent years, numerous scholars have confirmed that miRNA molecules in tumor tissue are novel markers for clinical tumor diagnosis. Research has indicated that miRNAs can stably exist in serum (5). Therefore, circulatory miRNAs have attracted extensive attention as novel biomarkers (5). Moreover, their potential to serve as disease diagnostic markers has been recognized (6).

The PI3K/Akt signal transduction pathway includes PI3K, Akt and their downstream effector molecules (7). PI3K is an important intracellular kinase, the excessive activation of which plays an important role in tumor genesis. Akt is highly homologous to $\mathrm{v}$-Akt, the virus oncogene inducing leukemia in mice (8). It is a major effector molecule of PI3K, the excessive activation of which can inhibit or activate its downstream target proteins (8). In this way, it may induce infinite cell proliferation through multiple pathways (8). PI3K can be activated through various pathways, thus producing an important product, PI-3,4,5-P3 (PIP3). PIP3 thereby serves as an intracellular second messenger to bind with Akt. Moreover, it can phosphorylate Akt and changes its conformation (9). In the meantime, it prompts the translocation of Akt from the cytoplasm to the cell membrane. This can activate its downstream target protein and promote cell survival by mediating growth factors and insulin (9).

Survivin is a new member of the anti-apoptosis protein family discovered in 1997. It is specifically expressed in human and mouse embryonic development tissues and most 
human tumor cells (10). However, it can only be observed in thymus, testicle and secretory endometrium in normal adult tissue (10). Its major function is to inhibit tumor cell apoptosis and promote tumor cell proliferation (11). Moreover, it is also related to tumor sensitivity to chemotherapy drugs and prognosis (11). The tissue specificity and function diversity of survivin has rendered it a new 'hotspot' in the field of tumor research (12). The present study was designed to assess the expression of miR-542-3p in human colon cancer and investigate the possible molecular mechanisms underlying the effects of miR-542-3p on the growth and invasion of colon cancer cells.

\section{Materials and methods}

Patients with colon cancer. Serum samples of patients with colon cancer $(n=12)$ and healthy volunteers $(n=6)$ were collected after centrifugation at $2,000 \mathrm{x}$ g for $10 \mathrm{~min}$ at $4^{\circ} \mathrm{C}$, and saved at $-80^{\circ} \mathrm{C}$. The study was approved by the institutional medical Ethics Committee of The Second Affiliated Hospital of Harbin Medical University.

RNA extraction and real-time PCR. TRIzol reagent (Life Technologies, Carlsbad, CA, USA) was used to isolate total RNA from cultured cells or samples. The PrimeScript ${ }^{\mathrm{TM}}$ RT Master Mix (Takara, Dalian, China) was used to synthesize first-strand cDNA using $100 \mathrm{ng}$ total RNA. miRNA expression was determined by RT-PCR using Power SYBR-Green PCR Master Mix (Carlsbad, CA, USA). The reactions were incubated at $95^{\circ} \mathrm{C}$ for $10 \mathrm{~min}$, followed by 40 cycles of $95^{\circ} \mathrm{C}$ for $30 \mathrm{sec}$ and $60^{\circ} \mathrm{C}$ for $30 \mathrm{sec}$.

Cell culture and treatments. Human SW620 cells were purchased from the American Type Culture Collection (ATCC; Manassas, VA, USA) and were maintained in Dulbecco's modified Eagle's medium (DMEM) containing 10\% fetal bovine serum (FBS) (both from Invitrogen, Carlsbad, CA, USA) at $37^{\circ} \mathrm{C}$ with $5 \% \mathrm{CO}_{2}$. miR-542-3p, anti-miR-542-3p and negative mimics were synthesized by GenePharma (Shanghai, China). SW620 cells were transfected with miR-542-3p, anti-miR542-3p and negative mimics using Lipofectamine 2000 (Invitrogen).

Cell viability assay. After transfection for 24, 48 and 72 h, SW620 cells were stained using Cell Counting Kit-8 (Beyotime, Shanghai, China) at $37^{\circ} \mathrm{C}$ for $1-2 \mathrm{~h}$. Cell viability was examined by measuring absorbance at $450 \mathrm{~nm}$ (Tecan Group Ltd., Männedorf, Switzerland).

Apoptosis assay and caspase-3/-9 activity. After transfection for $48 \mathrm{~h}$, SW620 cells were harvested and stained with Annexin V-PE and propidium iodide using an apoptosis kit (BD Pharmingen, Franklin Lakes, NJ) for 15 min in darkness. The apoptotic rate was determined by a flow cytometer (Beckman Coulter, Inc., Miami, FL, USA). Proteins were isolated from cultured cells after transfection using lysis buffer and measured using BCA assay (both from Beyotime). Proteins $(5 \mu \mathrm{g})$ were used to determine caspase-3/-9 activity using caspase-3/-9 activity kits. Caspase-3/-9 activity were examined by measuring absorbance at $405 \mathrm{~nm}$ (Tecan Group Ltd.).

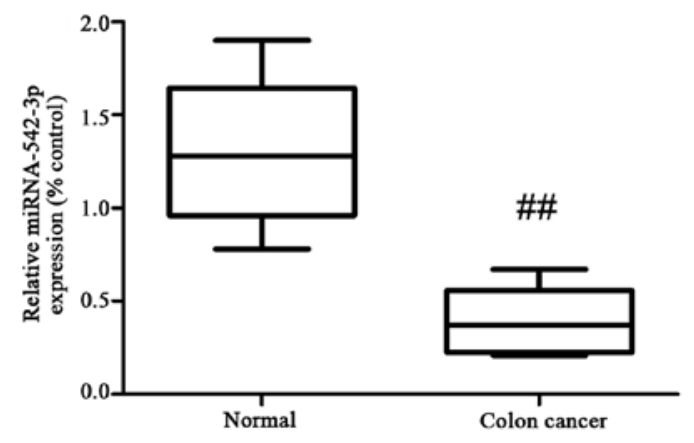

Figure 1. miR-542-3p expression in the serum of normal healthy controls (nornal) and colon cancer patients (colon cancer); ${ }^{\# \#} \mathrm{p}<0.01$ vs. the control group.

Transwell invasion assay. After transfection for $24 \mathrm{~h}, \mathrm{SW} 620$ cells $\left(2 \times 10^{5}\right.$ cells $\left./ \mathrm{ml}\right)$ were seeded in 24-well Transwells coated with Matrigel ( $8-\mu \mathrm{m}$ pore size; BD Biosciences, San Jose, CA, USA) using DMEM containing 1\% FBS. The cells remaining in the upper chamber were removed by cotton swabs following $24 \mathrm{~h}$ of incubation and cells in the lower surface were stained with hematoxylin after the cells were fixed with formaldehyde solution.

Western blotting. Proteins were isolated from cultured cells after transfection using lysis buffer (and measured using BCA (both from Beyotime). Proteins (30-50 $\mu \mathrm{g}$ ) were then subjected to sodium dodecyl sulfate-polyacrylamide gel electrophoresis (SDS-PAGE) for separation before being transferred onto a polyvinylidene difluoride (PVDF) membrane (Millipore, Billerica, MA, USA). The membrane was blocked with 5\% milk-in Tris-buffered saline with Tween-20 (TBST) for $1 \mathrm{~h}$ at $37^{\circ} \mathrm{C}$ and protein were detected by incubation with Bax, PI3K and p-AKT, survivin and GAPDH (Cell Signaling Technology, Inc., Danvers, MA, USA) antibodies overnight at $37^{\circ} \mathrm{C}$. The membranes were subsequently incubated with a goat anti-rabbit horseradish peroxidase secondary antibody (1:5,000; Cell Signaling Technology, Inc.) at $37^{\circ} \mathrm{C}$ for $1 \mathrm{~h}$. Protein blots were visualized with enhanced chemiluminescent substrate (Thermo Fisher Scientific, Inc., Waltham, MA, USA).

Statistical analyses. Data are presented as mean \pm SD. Statistical comparisons were performed by one-way ANOVA followed by Dunnett's t-test. $\mathrm{p}<0.05$ was considered to indicate a statistically significant difference.

\section{Results}

miR-542-3p expression. To determine the expression of miR-542-3p in clinical serum samples, we collected 6 pairs of human colon cancer samples and healthy controls. Our results showed that the expression levels of miR-542-3p were downregulated in the serum samples of the patients with colon cancer, compared with the levels in the control group (Fig. 1).

Silencing of miR-542-3p expression promotes cell viability of colon cancer. Due to the downregulated expression of miR-542-3p in human colon cancer serum samples, we 
A

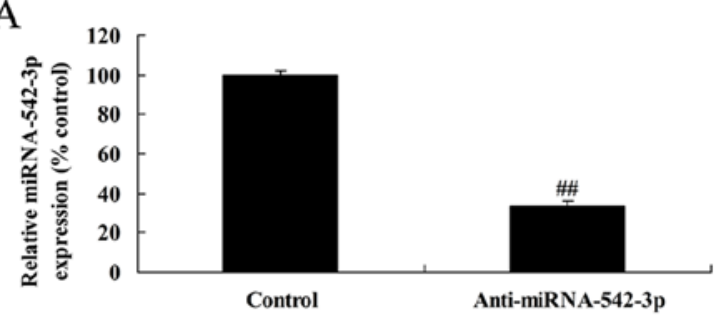

C

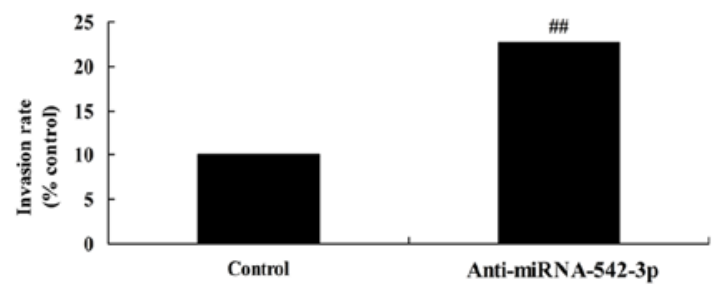

B

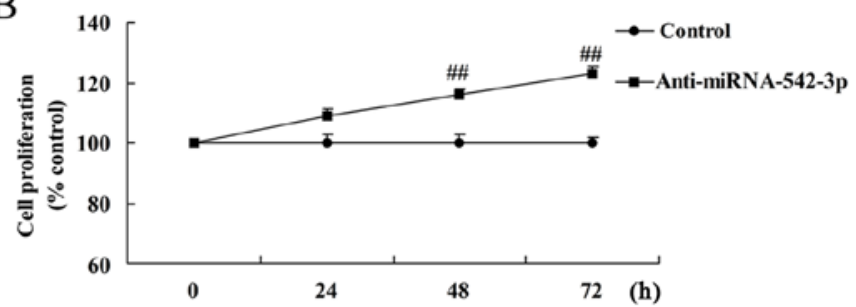

$\mathrm{D}$

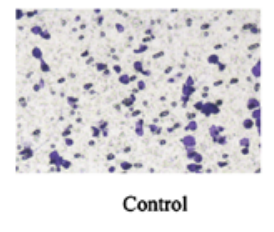

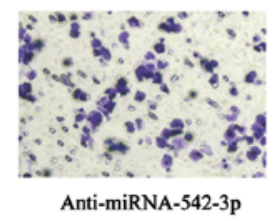

Figure 2. Silencing of miR-542-3p expression promotes cell viability and invasion of colon cancer. (A) Relative miRNA-542-3p expression, (B) cell viability and (C) invasion by statistical analysis. (D) Images of the migration assay (magnification, $x 10$ ). Control, negative control group; anti-miRNA-542-3p, silenced miR-542-3p group; ${ }^{\# \#}<0.01$ vs. the control group.

A

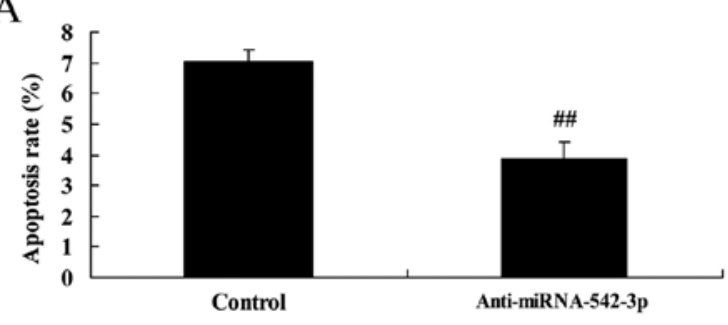

$\mathrm{C}$

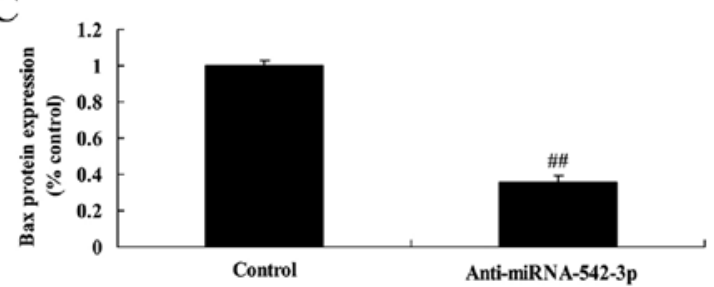

B

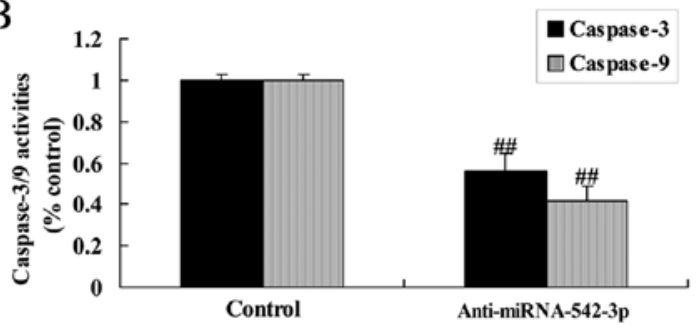

$\mathrm{D}$

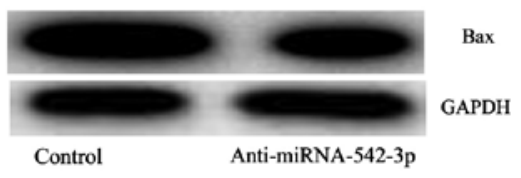

Figure 3. Silencing of miR-542-3p expression inhibits the apoptosis of colon cancer. (A) Apoptosis rate, (B) caspase-3/-9 activity and (C) Bax protein expression as determined by statistical analysis. (D) Western blot analysis. Control, negative control group; anti-miRNA-542-3p, silenced miR-542-3p group; ${ }^{\# \#<0.01 ~ v s . ~}$ the control group.

speculated that miR-542-3p may act as a tumor-suppressor in the development of colon cancer. The expression of miR-542-3p in the anti-miR-542-3p-transfected cells was lower than that in the control group (Fig. 2A). Silencing of miR-542-3p expression significantly promoted cell viability (Fig. 2B) and invasion of colon cancer cells compared with the control group (Fig. 2C and D).

Silencing of miR-542-3p expression inhibits the apoptosis of colon cancer cells. We demonstrated that the silencing of miR-542-3p expression significantly inhibited apoptosis, caspase-3/-9 activities and Bax protein expression in the colon cancer cells compared with the control group (Fig. 3).

Silencing of miR-542-3p expression induces PI3K/AKT/ survivin signaling in colon cancer cells. Moreover, we explored the mechanism underlying the miR-542-3p-mediated apop- tosis of colon cancer cells. We analyzed PI3K/AKT/survivin signaling. Silencing of miR-542-3p expression significantly induced PI3K/AKT/survivin signaling in the colon cancer cells, compared with the control group (Fig. 4).

Overexpression of $m i R-542-3 p$ inhibits the viability of colon cancer cells. Next, we induced miR-542-3p expression to explore the effect of miR-542-3p on the apoptosis of colon cancer cells. As shown in Fig. 5A, miR-542-3p expression in the cells transfected with miR-542-3p was higher than that of the control group. Cell viability and invasion of the colon cancer cells were significantly reduced by overexpression of miR-542-3p, compared with the control group (Fig. 5B-D).

Overexpression of miR-542-3p promotes the apoptosis of colon cancer cells. Overexpression of miR-542-3p significantly induced apoptosis, caspase-3/-9 activity and Bax protein 
A
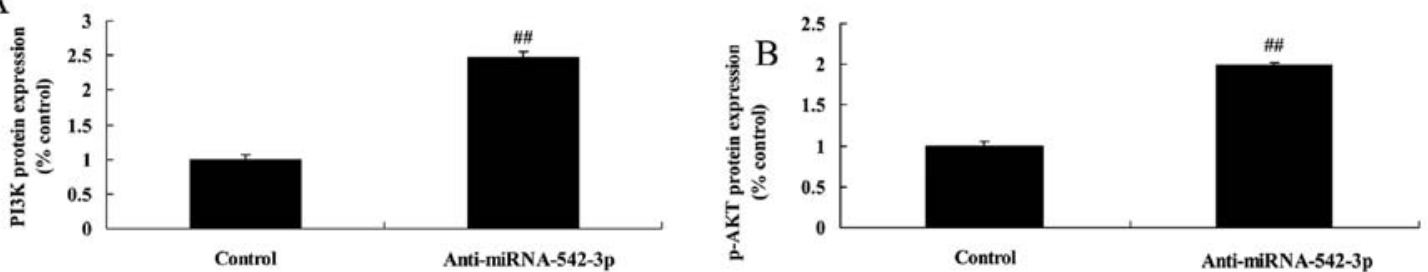

$\mathrm{D}$
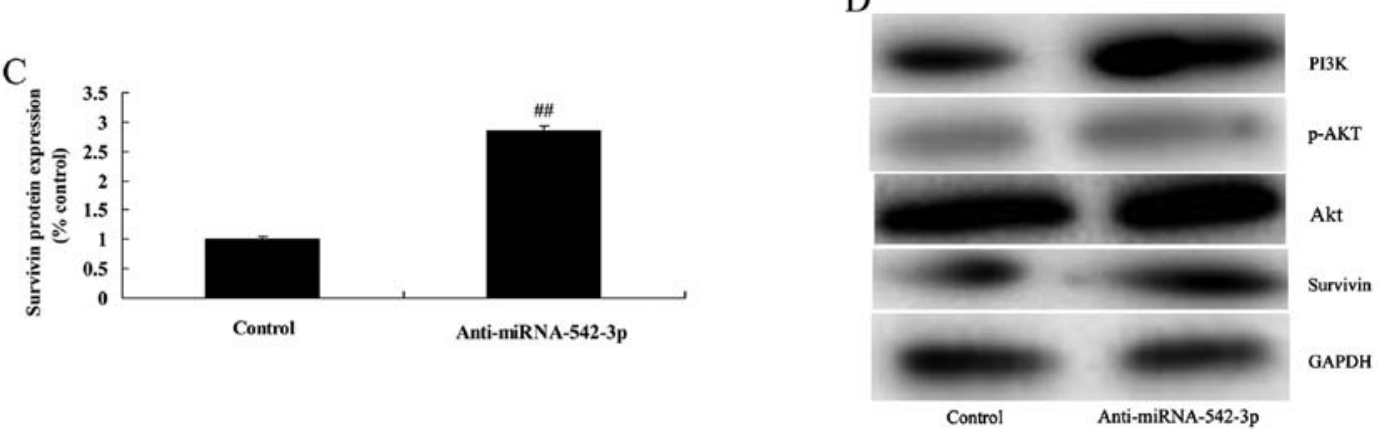

Figure 4. Silencing of miR-542-3p expression induces PI3K/AKT/survivin signaling in colon cancer. (A) PI3K, (B) p-AKT and (C) survivin protein expression as determined by statistical analysis. (D) Western blot analysis. Control, negative control group; anti-miRNA-542-3p, silenced miR-542-3p group; \#\# $<0.01$ vs. the control group.

A

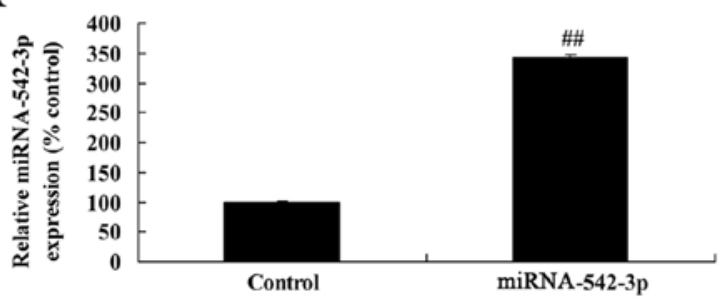

$\mathrm{C}$

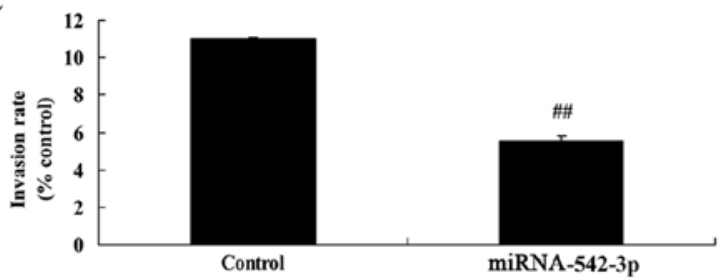

B

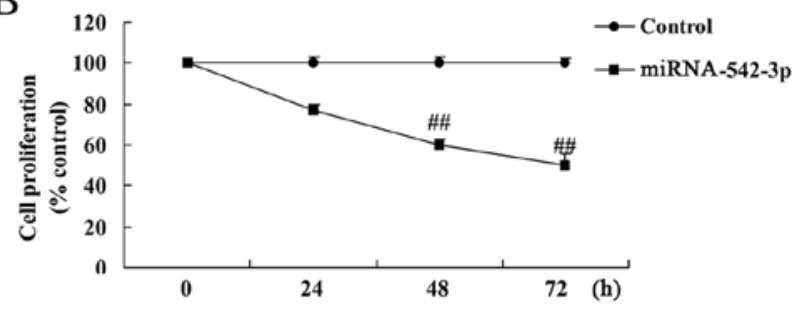

D

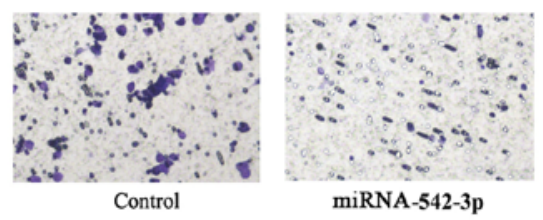

Figure 5. Overexpression of miR-542-3p inhibits cell viability of colon cancer. (A) Relative miRNA-542-3p expression, (B) cell viability and (C) invasion as determined by statistical analysis. (D) Images of the migration assay (magnification, x10). Control, negative control group; miRNA-542-3p, overexpression miR-542-3p group; ${ }^{\# \#}$ p $<0.01$ vs. the control group.

expression in the colon cancer cells, compared with the control group (Fig. 6).

Overexpression of miR-542-3p suppresses PI3K/AKT/ survivin signaling in the colon cancer cells. Overexpression of miR-542-3p significantly suppressed PI3K/AKT/survivin signaling in the colon cancer cells, compared with the control group (Fig. 7). There results showed that miR-542-3p regulates $\mathrm{PI} 3 \mathrm{~K} / \mathrm{AKT}$ /survivin signaling to affect the growth of colon cancer cells.

Inhibition of PI3K suppresses PI3K/AKT/survivin signaling in the colon cancer cells following miR-542-3p transfection.
We performed bioinformatic analysis to identify the role of PI3K in the function of miR-542-3p on the apoptosis of colon cancer cells. As shown in Fig. 8, PI3K inhibitor (100 nM, LY294002), significantly suppressed PI3K/AKT/survivin signaling in the colon cancer cells following miR-542-3p transfection, when compared with the miR-542-3p group (Fig. 8).

Inhibition of PI3K inhibits the growth of colon cancer cells following miR-542-3p transfection. Cell viability and invasion of colon cancer cells were significantly reduced by overexpression of miR-542-3p and inhibition of PI3K, compared with the miR-542-3p group (Fig. 9). 
A

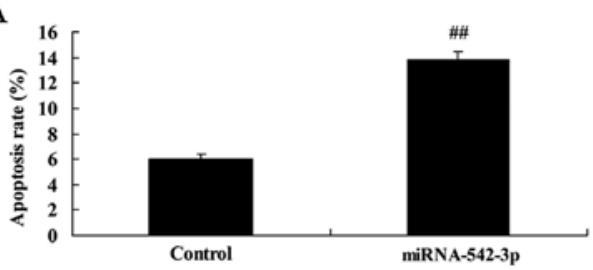

C

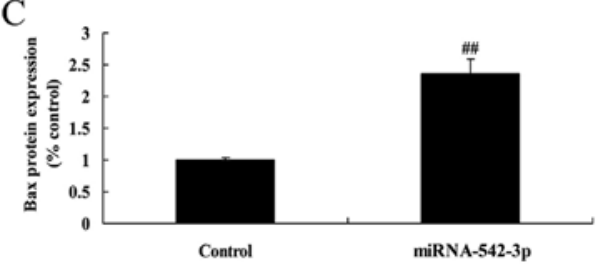

B

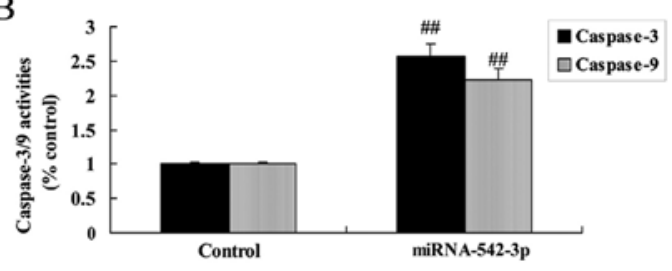

$\mathrm{D}$

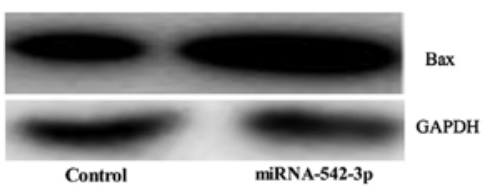

Figure 6. Overexpression of miR-542-3p promotes the apoptosis of colon cancer. (A) Apoptosis rate, (B) caspase-3/-9 activity and (C) Bax protein expression as determined by statistical analysis. (D) Western blot analysis. Control, negative control group; miRNA-542-3p, overexpression miR-542-3p group; ${ }^{\# \# ~}<0.01$ vs. the control group.

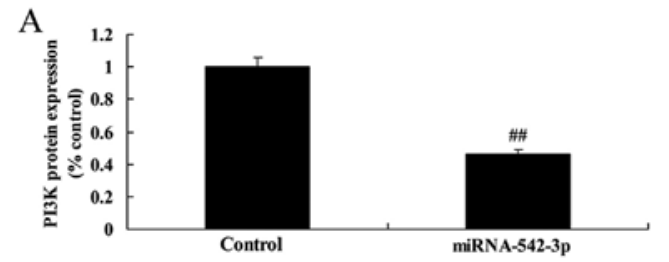

C

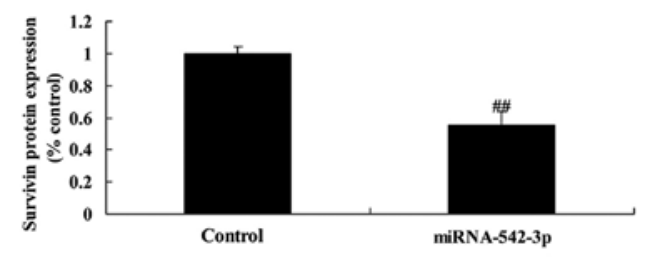

B

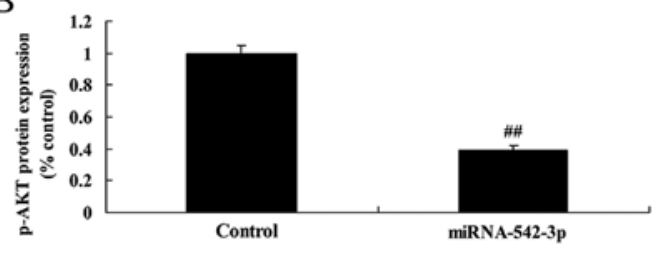

$\mathrm{D}$

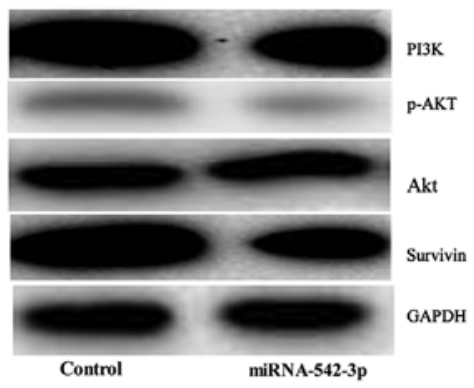

Figure 7. Overexpression of miR-542-3p suppresses PI3K/AKT/survivin signaling in colon cancer. (A) PI3K, (B) p-AKT and (C) survivin protein expression as determined by statistical analysis. (D) Western blot analysis. Control, negative control group; miRNA-542-3p, overexpression miR-542-3p group; ${ }^{* \#} \mathrm{p}<0.01$ vs. the control group.

A

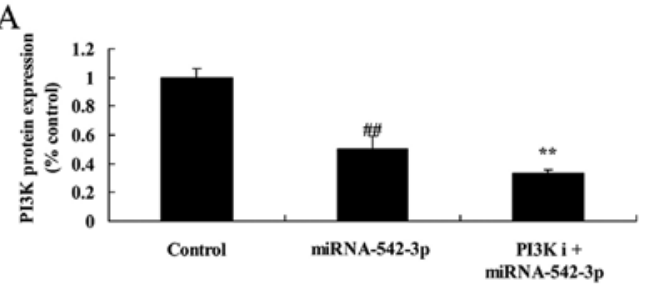

$\mathrm{C}$

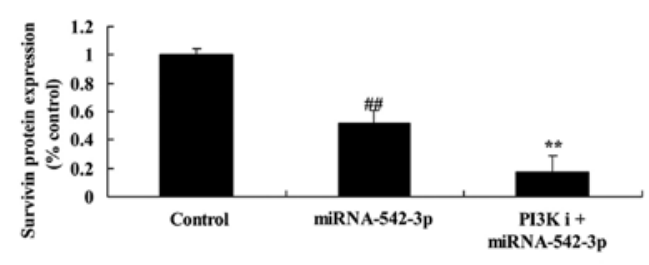

B

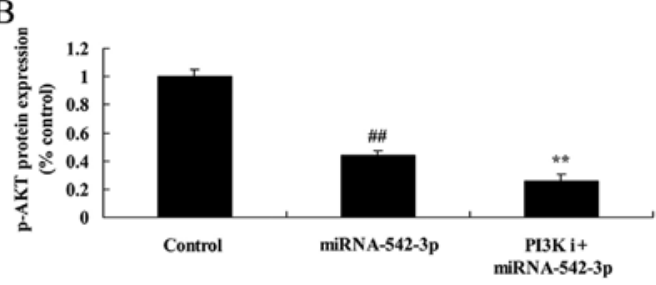

$\mathrm{D}$

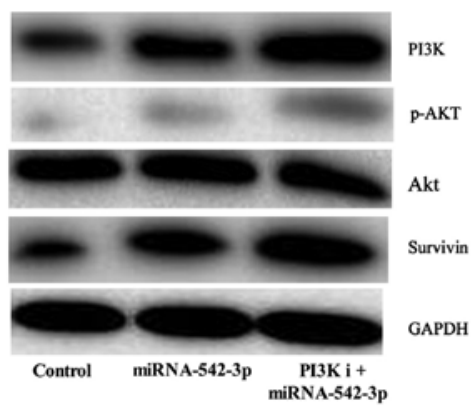

Figure 8. Inhibition of PI3K suppresses PI3K/AKT/survivin signaling in colon cancer following miR-542-3p. (A) PI3K, (B) p-AKT and (C) survivin protein expression as determined by statistical analysis. (D) Western blot analysis. Control, negative control group; miRNA-542-3p, overexpression miR-542-3p group; PI3K i + miRNA-542-3p, overexpression miR-542-3p and PI3K inhibitor group; ${ }^{\# \#} \mathrm{p}<0.01$ vs. the control group, ${ }^{* *} \mathrm{p}<0.01$ vs. overexpression miR-542-3p group. 


\section{A}

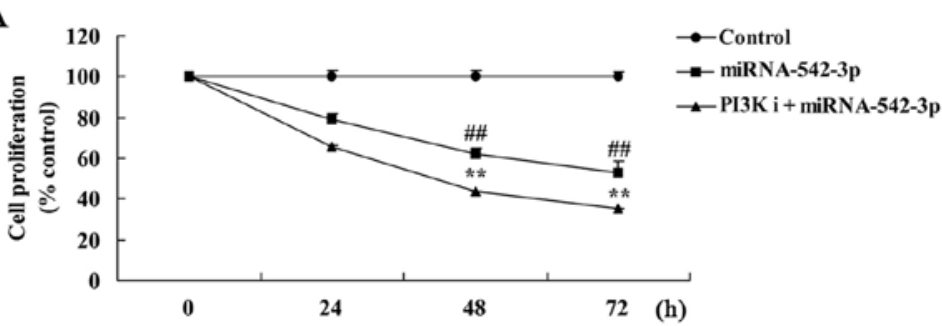

B

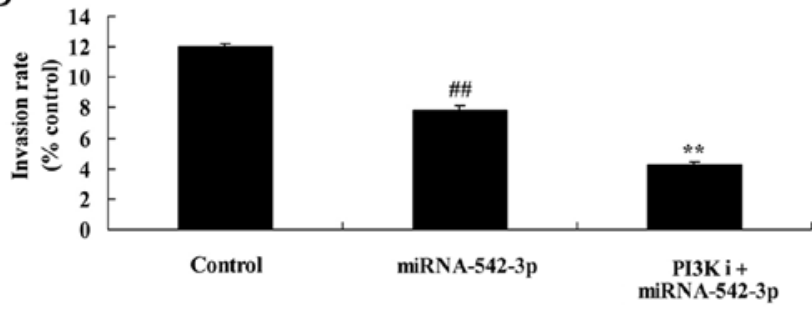

$\mathrm{C}$

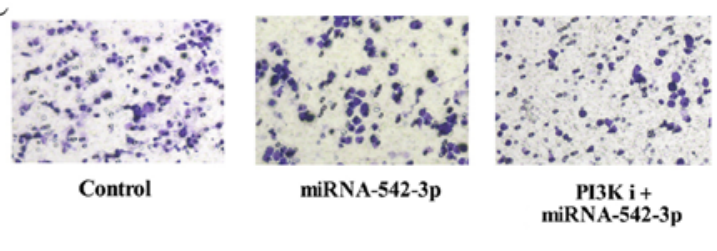

Figure 9. Inhibition of PI3K suppresses cell growth of colon cancer following miR-542-3p transfection. (A) Cell viability and (B) invasion as determined by statistical analysis. (C) Images of the migration assay (magnification, $x 10$ ). Control, negative control group; miRNA-542-3p, overexpression miR-542-3p group; PI3K i + miRNA-542-3p, overexpression miR-542-3p and PI3K inhibitor group; ${ }^{\# \#} \mathrm{p}<0.01$ vs. the control group, ${ }^{* *} \mathrm{p}<0.01$ vs. overexpression miR-542-3p group.

A

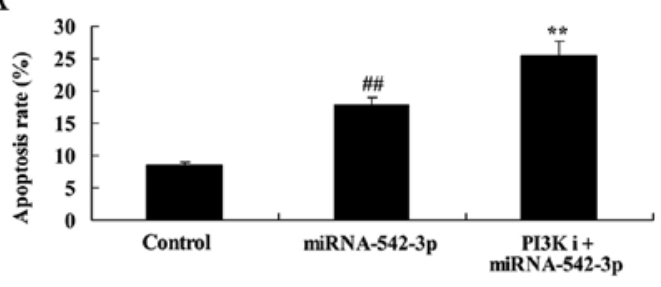

$\mathrm{C}$

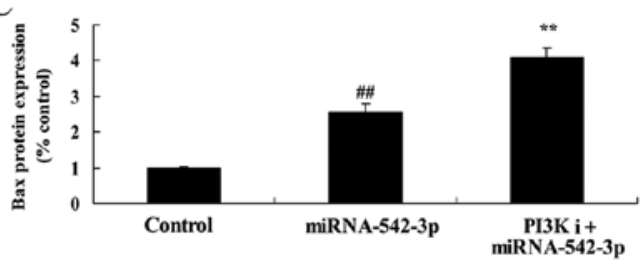

$\mathrm{B}$

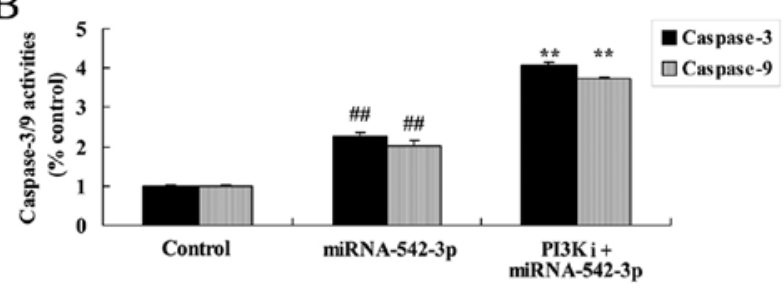

D

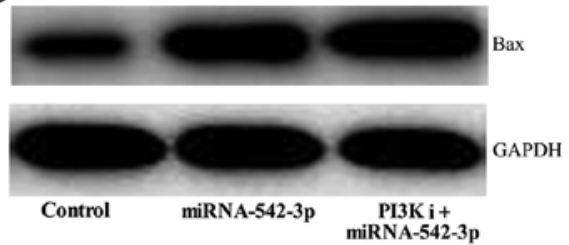

Figure 10. Inhibition of PI3K promotes cell apoptosis of colon cancer following miR-542-3p transfection. (A) Apoptosis rate, (B) caspase-3/-9 activity and (C) Bax protein expression as determined by statistical analysis. (D) Western blot analysis. Control, negative control group; miRNA-542-3p, overexpression miR-542-3p group; PI3K i + miRNA-542-3p, overexpression miR-542-3p and PI3K inhibitor group; ${ }^{\# \#} \mathrm{p}<0.01$ vs. the control group, ${ }^{* *} \mathrm{p}<0.01$ vs. overexpression miR-542-3p group.

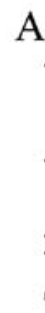$$
\text { I. }
$$
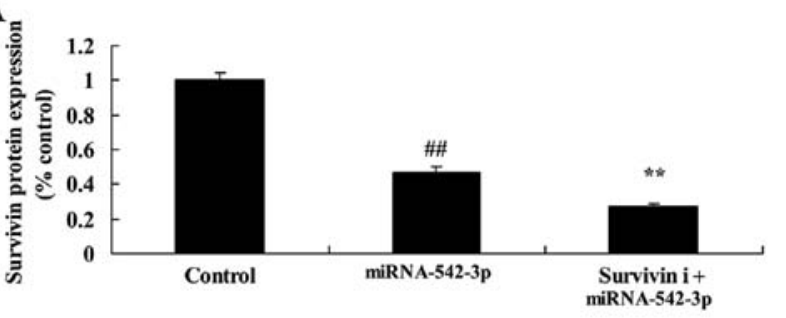

B

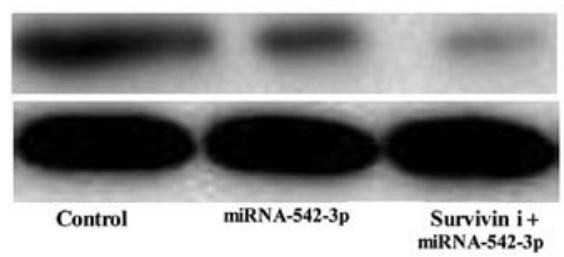

Figure 11. Inhibition of survivin suppresses survivin signaling in colon cancer following miR-542-3p transfection. (A) Survivin protein expression as determined by statistical analysis. (B) Western blot analysis. Control, negative control group; miRNA-542-3p, overexpression miR-542-3p group; survivin i + miRNA542-3p, overexpression miR-542-3p and survivin inhibitor group; ${ }^{\# \#} \mathrm{p}<0.01$ vs. the control group, ${ }^{* * *} \mathrm{p}<0.01$ vs. overexpression miR-542-3p group.

Inhibition of PI3K promotes the apoptosis of colon cancer cells following miR-542-3p transfection. Apoptosis, caspase-3 activity and Bax protein expression in the colon cancer cells following miR-542-3p transfection were significantly 
A

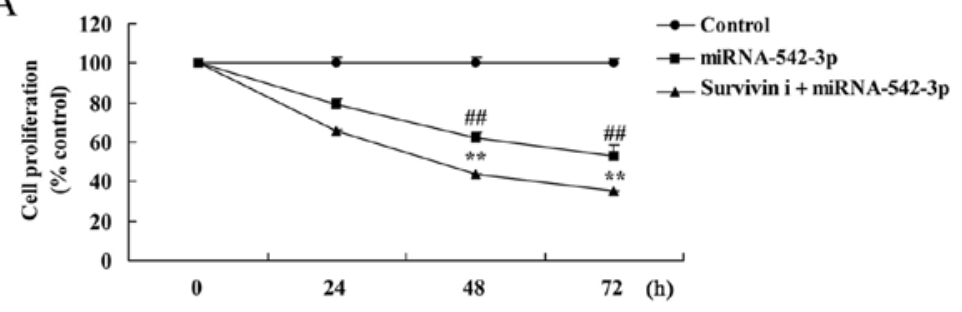

$\mathrm{B}$

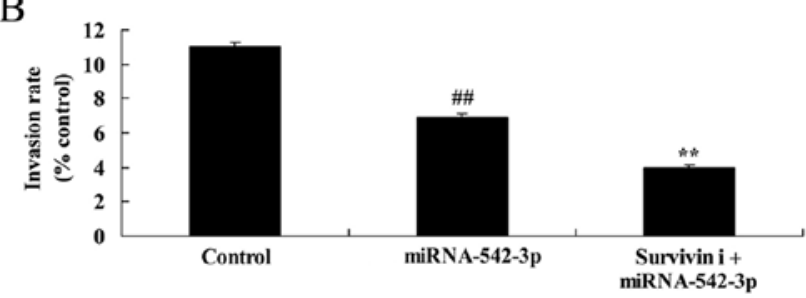

$\mathrm{C}$

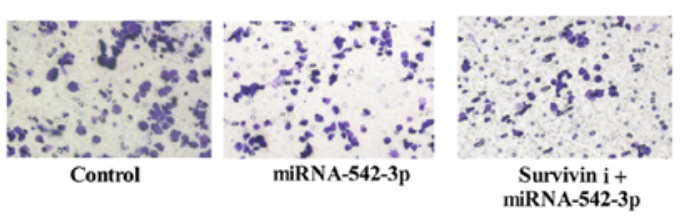

Figure 12. Inhibition of survivin suppresses cell growth of colon cancer following miR-542-3p transfection. (A) Cell viability and (B and C) invasion of colon cancer cells. Control, negative control group; miRNA-542-3p, overexpression miR-542-3p group; survivin i + miRNA-542-3p, overexpression miR-542-3p and survivin inhibitor group; ${ }^{\# \#} \mathrm{p}<0.01$ vs. the control group, ${ }^{* *} \mathrm{p}<0.01$ vs. overexpression miR-542-3p group.

A
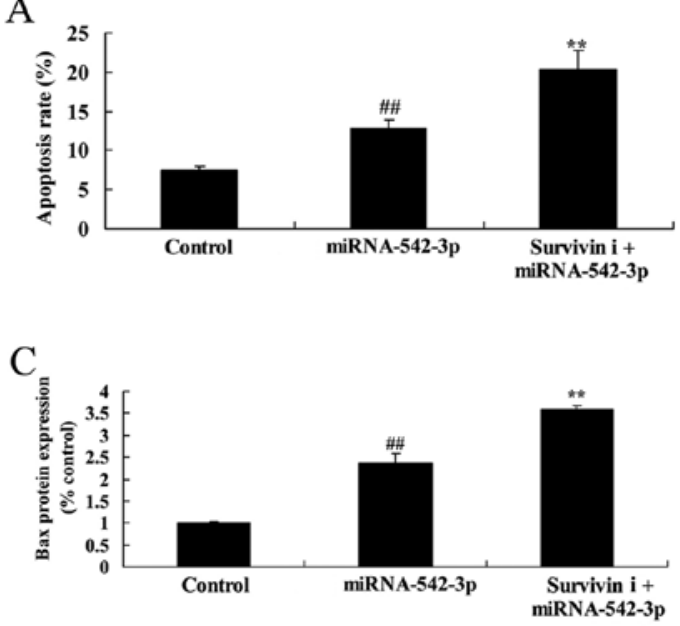

$\mathrm{B}$

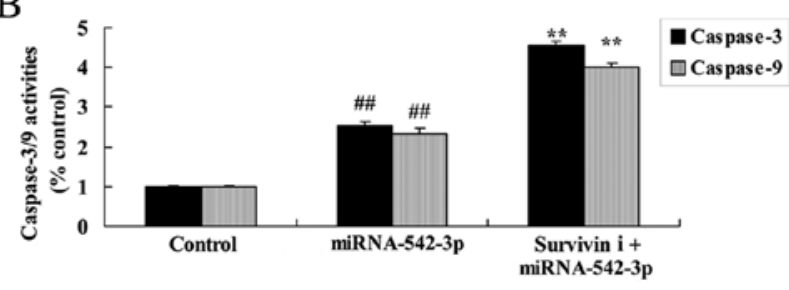

$\mathrm{D}$

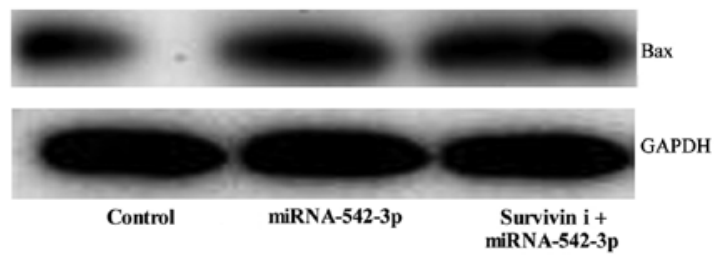

Figure 13. Inhibition of survivin promotes cell apoptosis of colon cancer cells following miR-542-3p transfection. (A) Apoptosis rate, (B) caspase-3/-9 activity and (C) Bax protein expression as determined by statistical analysis. (D) Western blot analysis. Control, negative control group; miRNA-542-3p, overexpression miR-542-3p group; survivin $\mathrm{i}+$ miRNA-542-3p, overexpression miR-542-3p and survivin inhibitor group; ${ }^{\# \#} \mathrm{p}<0.01$ vs. the control group, ${ }^{* *} \mathrm{p}<0.01$ vs. overexpression miR-542-3p group.

increased by the inhibition of PI3K, compared with the miR542-3p group (Fig. 10).

Inhibition of survivin suppresses the survivin expression in the colon cancer cells. To investigate whether knockdown of survivin influences the anticancer effects of miR-542-3p in colon cancer cells, survivin inhibitor (YM155) was used to reduce survivin expression in the colon cancer cells. As shown in Fig. 11, survivin inhibitor significantly suppressed survivin signaling in the colon cancer cells transfected with miR-542-3p, compared with the miR-542-3p group.

Inhibition of survivin suppresses the growth and invasion of colon cancer cells following miR-542-3p transfection. Fig. 12 shows that inhibition of survivin significantly suppressed cell growth and invasion of colon cancer cells following miR542-3p transfection, compared with the miR-542-3p group.

Inhibition of survivin promotes the apoptosis of colon cancer cells following miR-542-3p transfection. Finally, the inhibition of survivin significantly promoted cell apoptosis, caspase-3/-9 activity and Bax protein expression in the colon cancer cells following miR-542-3p transfection (Fig. 13).

\section{Discussion}

Colon cancer is one of the most common digestive system neoplasms (13). The gold standard for the clinical diagnosis of colon cancer is electronic colonoscopy diagnostic technology (14). Such technology requires specific 
equipment, technical support, and high proficiency in the operation of operators (1). Furthermore, at the time of diagnosis it may have invaded into the human body. Thus, it is associated with risks of complications of hemorrhage and perforation (14). Therefore, developing novel diagnostic methods is necessary to alleviate patient suffering and reduce the risk of mortality (14). In the present study, we found that expression levels of miR-542-3p in serum were downregulated in patients with colon cancer.

Recent studies have found that deletion of the PTEN gene is observed in malignant tumors, such as lung cancer, endometrial cancer and breast cancer (15). This may result in the dysfunction of the PI3K/Akt signaling pathway (15). Consequently, gene expression in this pathway may become one of the important indices for predicting the prognosis of malignant tumors. Meanwhile, small-molecule inhibitors targeting this pathway may effectively suppress malignant tumor cell growth and achieve gene therapy (16). The present study showed that the silencing of miR-542-3p expression significantly promoted cell viability, and inhibited apoptosis through suppression of PI3K and p-AKT and survivin protein expression in human colon cancer. Kureel et al showed that miR-542-3p suppresses osteoblast cell proliferation and differentiation through BMP-7/PI3K-survivin signaling in bone formation (17). These results support our current findings and suggest a potential mechanism for the tumor-suppressor role of miR-542-3p in human colon cancer mediated through PI3K/ AKT/survivin signals.

Excessive activation of PI3K can lead to that of Akt. Thus, it may break the balance of the PI3K/Akt signaling pathway (18). This may result in excessive cell proliferation and give rise to carcinogenesis (19). It is known that activated PI3K can induce the genesis of multiple malignant tumors, such as leukemia, prostate cancer and lymphoma (19). At the same time, it is verified in experiments that excessive activation of PI3K can lead to the genesis of colon cancer (19). Evolution of PI3K protein in colon cancer shows an increasing trend. In other words, it shows low or even negative expression in normal large colorectal mucosa or polyps. However, it displays significantly elevated expression in colon cancer tissues (20). The present study showed that PI3K inhibitor (LY294002) suppressed the $\mathrm{PI} 3 \mathrm{~K} / \mathrm{AKT} /$ survivin signal and increased the anticancer effects of miR-542-3p on apoptosis in colon cancer. Cai et al found that miR-542-3p suppressed the tumor cell invasion of human astrocytoma via targeting the AKT pathway (21).

Experiments in vitro indicate that survivin can inhibit cell apoptosis by directly or indirectly interfering with caspase function (22). Direct action of survivin on caspases mainly represents the process of caspase- 3 and -7 activity suppression and cell apoptosis blocking (22). Moreover, survivin indirectly inhibits caspase through P21. Its mechanism is that survivin forms the survivin-CDK4 complex with the cell cycle control factor CDK4 (23). In this way, P21 can be released from the CDK4 complex, which can further bind with mitochondrial caspase-3. As a result, it may inhibit its activity and prevent cell apoptosis. Survivin is expressed in the G2/M phase of the cell cycle (23). At the early stage of mitosis, survivin develops a specific saturable reaction with mitotic spindle microtubule. However, it is regulated by microtubule dynamics (24). The interaction between survivin and the microtubule can be interfered with using microtubule inhibitors. This results in the loss of anti-apoptotic activity of survivin and the activation of caspase-3. Thus, it can induce cell apoptosis (25). This result indicates that survivin partly regulates mitosis through its action on spindle microtubule. Thereby, it can exert an antiapoptotic effect (25). In the present study, survivin inhibitor (YM155) suppressed the PI3K/AKT/survivin signal and increased the anticancer effects of miR-542-3p on apoptosis in colon cancer. Zhang et al reported that miR-542-3p suppresses cell proliferation by post-transcriptionally regulating survivin in bladder cancer cells (26).

In conclusion, the data in the present study revealed that upregulation of miR-542-3p suppressed the growth and invasion of colon cancer cells through PI3K/AKT/survivin signaling, highlighting a novel therapeutic approach for the treatment of colon cancer.

\section{References}

1. Floodeen H, Lindgren R, Hallböök $O$ and Matthiessen $P$ : Evaluation of long-term anorectal function after low anterior resection: A 5-year follow-up of a randomized multicenter trial. Dis Colon Rectum 57: 1162-1168, 2014.

2. Hong YS, Nam BH, Kim KP, Kim JE, Park SJ, Park YS, Park JO, Kim SY, Kim TY, Kim JH, et al: Oxaliplatin, fluorouracil, and leucovorin versus fluorouracil and leucovorin as adjuvant chemotherapy for locally advanced rectal cancer after preoperative chemoradiotherapy (ADORE): An open-label, multicentre, phase 2, randomised controlled trial. Lancet Oncol 15: 1245-1253, 2014.

3. Reima H, Saar H, Innos K and Soplepmann J: Methylene blue intra-arterial staining of resected colorectal cancer specimens improves accuracy of nodal staging: A randomized controlled trial. Eur J Surg Oncol 42: 1642-1646, 2016.

4. Liu K, Yao H, Lei S, Xiong L, Qi H, Qian K, Liu J, Wang P and Zhao H: The miR-124-p63 feedback loop modulates colorectal cancer growth. Oncotarget 8: 29101-29115, 2017.

5. Monzo M, Santasusagna S, Moreno I, Martinez F, Hernández R, Muñoz C, Castellano JJ, Moreno J and Navarro A: Exosomal microRNAs isolated from plasma of mesenteric veins linked to liver metastases in resected patients with colon cancer. Oncotarget 8: 30859-30869, 2017.

6. Wu K, Zhao Z, Ma J, Chen J, Peng J, Yang S and He Y: Deregulation of miR-193b affects the growth of colon cancer cells via transforming growth factor- $\beta$ and regulation of the SMAD3 pathway. Oncol Lett 13: 2557-2562, 2017.

7. Nagappan A, Lee WS, Yun JW, Lu JN, Chang SH, Jeong JH, Kim GS, Jung JM and Hong SC: Tetraarsenic hexoxide induces G2/M arrest, apoptosis, and autophagy via PI3K/Akt suppression and p38 MAPK activation in SW620 human colon cancer cells. PLoS One 12: e0174591, 2017.

8. Zhang LL, Mu GG, Ding QS, Li YX, Shi YB, Dai JF and Yu HG: Phosphatase and tensin homolog (PTEN) represses colon cancer progression through inhibiting paxillin transcription via PI3K/AKT/NF-кB pathway. J Biol Chem 290: 15018-15029, 2015.

9. Gao Y, Xiao X, Zhang C, Yu W, Guo W, Zhang Z, Li Z, Feng X, Hao J, Zhang K, et al: Melatonin synergizes the chemotherapeutic effect of 5-fluorouracil in colon cancer by suppressing PI3K/AKT and NF- $\mathrm{KB} / \mathrm{iNOS}$ signaling pathways. J Pineal Res 62: e12380, 2017.

10. Waligórska-Stachura J, Jankowska A, Waśko R, Liebert W, Biczysko M, Czarnywojtek A, Baszko-Błaszyk D, Shimek V and Ruchała M: Survivin - prognostic tumor biomarker in human neoplasms - review. Ginekol Pol 83: 537-540, 2012.

11. Hwang JS, Lee HC, Oh SC, Lee DH and Kwon KH: Shogaol overcomes TRAIL resistance in colon cancer cells via inhibiting of survivin. Tumour Biol 36: 8819-8829, 2015.

12. Hsu YF, Sheu JR, Lin CH, Yang DS, Hsiao G, Ou G, Chiu PT, Huang YH, Kuo WH and Hsu MJ: Trichostatin A and sirtinol suppressed survivin expression through AMPK and p38MAPK in HT29 colon cancer cells. Biochim Biophys Acta 1820: 104-115, 2012. 
13. Kim CW, Baek JH, Choi GS, Yu CS, Kang SB, Park WC, Lee $\mathrm{BH}$, Kim HR, Oh JH, Kim JH, et al: The role of primary tumor resection in colorectal cancer patients with asymptomatic, synchronous unresectable metastasis: Study protocol for a randomized controlled trial. Trials 17: 34, 2016.

14. Augestad KM, Norum J, Rose J and Lindsetmo RO: A prospective analysis of false positive events in a National Colon Cancer Surveillance Program. BMC Health Serv Res 14: 137, 2014.

15. Liu Y, Chen L, Ko TC, Fields AP and Thompson EA: Evil is a survival factor which conveys resistance to both TGFbeta- and taxol-mediated cell death via PI3K/AKT. Oncogene 25: 3565-3575, 2006.

16. Tabusa H, Brooks T and Massey AJ: Knockdown of PAK4 or PAK1 inhibits the proliferation of mutant KRAS colon cancer cells independently of RAF/MEK/ERK and PI3K/AKT signaling. Mol Cancer Res 11: 109-121, 2013.

17. Kureel J, Dixit M, Tyagi AM, Mansoori MN, Srivastava K, Raghuvanshi A, Maurya R, Trivedi R, Goel A and Singh D: miR-542-3p suppresses osteoblast cell proliferation and differentiation, targets BMP-7 signaling and inhibits bone formation. Cell Death Dis 5: e1050, 2014.

18. Li XY and Wang X: The role of human cervical cancer oncogene in cancer progression. Int J Clin Exp Med 8: 8363-8368, 2015.

19. Jang HJ, Hong EM, Kim M, Kim JH, Jang J, Park SW, Byun HW, Koh DH, Choi MH, Kae SH, et al: Simvastatin induces heme oxygenase-1 via NF-E2-related factor 2 (Nrf2) activation through ERK and PI3K/Akt pathway in colon cancer. Oncotarget 7 : 46219-46229, 2016.

20. Moench R, Grimmig T, Kannen V, Tripathi S, Faber M, Moll EM, Chandraker A, Lissner R, Germer CT, Waaga-Gasser AM, et al: Exclusive inhibition of PI3K/Akt/mTOR signaling is not sufficient to prevent PDGF-mediated effects on glycolysis and proliferation in colorectal cancer. Oncotarget 7: 68749-68767, 2016.
21. Cai J, Zhao J, Zhang N, Xu X, Li R, Yi Y, Fang L, Zhang L, Li M, Wu J, et al: MicroRNA-542-3p suppresses tumor cell invasion via targeting AKT pathway in human astrocytoma. J Biol Chem 290: 24678-24688, 2015.

22. Li W, Lee MR, Choi E and Cho MY: Clinicopathologic significance of survivin expression in relation to CD133 expression in surgically resected stage II or III colorectal cancer. J Pathol Transl Med 51: 17-23, 2017.

23. Wang R, Kang Y, Löhr CV, Fischer KA, Bradford CS, Johnson G, Dashwood WM, Williams DE, Ho E and Dashwood RH: Reciprocal regulation of $B M F$ and $B I R C 5$ (Survivin) linked to Eomes overexpression in colorectal cancer. Cancer Lett 381: 341-348, 2016.

24. Gao F, Zhang Y, Yang F, Wang P, Wang W, Su Y and Luo W: survivin promotes the invasion of human colon carcinoma cells by regulating the expression of MMP-7. Mol Med Rep 9: 825-830, 2014

25. Wang H, Li S, Luo X, Song Z, Long X and Zhu X: Knockdown of PARP6 or survivin promotes cell apoptosis and inhibits cell invasion of colorectal adenocarcinoma cells. Oncol Rep 37: 2245-2251, 2017

26. Zhang J, Wang S, Han F, Li J, Yu L, Zhou P, Chen Z, Xue S, Dai C and Li Q: MicroRNA-542-3p suppresses cellular proliferation of bladder cancer cells through post-transcriptionally regulating survivin. Gene 579: 146-152, 2016 